\title{
Upper limb mesomelic dysplasia
}

INSERM

\section{Source}

INSERM. (1999). Orphanet: an online rare disease and orphan drug data base. Upper limb mesomelic dysplasia. ORPHA:2497

This syndrome is an isolated upper limb mesomelic dysplasia. It has been described in four patients from two unrelated families (a man and his daughter, and a Lebanese man and his son). Patients present with ulnar hypoplasia with severe radial bowing, but normal stature. The mode of transmission is likely to be autosomal dominant with variable expressivity. 